\title{
Influence of Anthraquinone Addition Method on Alkaline Pulping of Kenaf Bast
}

\author{
Yoshito Ohtani, Takuro Noguchi, and Kazuhiko Sameshima
}

Faculty of Agriculture, Kochi University, Nankoku, Kochi, 783 Japan

\begin{abstract}
Kenaf bast was pulped by several alkaline cookings. Soda-anthraquinone pulping is superior to soda pulping and comparable to kraft pulping with respect to pulp yield and delignification ability. All of three commercial anthraquinone and its precursors were effective for kenaf bast pulping in a same level, but a little difference between kenaf bast and wood pulpings was found. Anthraquinone could enhance the delignification but could not contribute to any yield increase in the kraft pulping of kenaf bast. Kenaf bast fiber resembles the fibers from woody basts, like as kozo, mitsumata and so on. But the detailed characteristics should be further elucidated.
\end{abstract}

\section{Introduction}

Worldwide statistics are estimating the shortage of $\mathrm{fu}$ ture pulp sources and suggesting a neccesity in seeking new fiber sources other than the forests [1]. For the purpose of meeting the expansion of fiber requirements, kenaf (Hibiscus cannabinus L. and $H$. sabdariffd L.) has been proposed as one of the most promising fiber plants. Kenaf is now being widely recognized as an alternative fiber for the pulp and paper industries owing to the ex. tensive researches made by many countries.

In Japan, more than $99 \%$ of the pulp feedstocks is wood and a little attention is paid to non-wood pulp plants including kenaf. However, recent increase in the global environmental awareness to preserve the forests is opening a way for alternatives to the well established wood fiber sources, especially in the specialty paper market[2].

Kenaf is capable of producing both long and short fibers, i.e. bast (bark) and core fibers, which will be an advantage in competing against the wood fibers. The long fibers are expected as a substitution for the kozo (Brous. sonetia kazinoki Sieb.) and mitusmata (Edgeworthia papyrifera Sieb. et Zucc.) fibers used in the Japanese traditional handmade paper production and they have also a potential for sustaining the fiber sources of local papermaking industries [3].

Kenaf bast is found to be slightly more lignified than the kozo and mitsumata basts [4], therefore harder to be delignified by the conventional bast pulping. The present paper deals with a fundamental study on the alkaline pulping suitable for the kenaf bast.

\section{Experimental}

\subsection{Material}

Kenaf samples (H. cannabinus. Aokawa-3-gou) grown in Kochi in 1992 were harvested in October, avarage grow ing height was about 3.5 meters. The manually-separated kenaf basts were air-dried and cut to $3 \mathrm{~cm}$ for pulping experiments.

\subsection{Cooking Condition}

Alkaline cooking with soda, soda-anthraquinone de. rivatives (anthraquinone $(A Q)$, tetrahydroanthraquinone (THAQ), and disodiun-1, 4-dehydro-9, 10-dihydroxyanthracene (SAQ)), and kraft were compared using rotary autoclave. AQ was commercial reagent, THAQ and $S A Q$ were kindly supplied by Kawasaki Kasei Kogyo Co. SAQ is sodium salt of THAQ, and THAQ and SAQ are known to be more effective than $A Q[5]$. SAQ was added into the cooking sample under replacement of air with nitrogen. Cooking conditions are summarized in Table 1 .

\subsection{Properties of the Pulps}

The pulp yield, kappa number $[6]$, and pulp viscosity (7) were measured. The pulps for viscosity measurement were delignified in advance, in which $0.5 \mathrm{~g}$ (oven-dried) of each unbleached pulp was treated with sodium chlorite and acetic acid in the buffer solution $(\mathrm{pH} 3.5,0.3 \mathrm{M}$ sodium acetate) for $1 \mathrm{~h}$ at $65^{\circ} \mathrm{C}$. Dosages of sodium chlo- 
Table 1 Cooking Conditions

\begin{tabular}{c|c|c}
\hline & Soda or soda-AQ & Kraft \\
\hline $\begin{array}{c}\text { Active alkali } \\
\left(\text { as } \mathrm{Na}_{2} \mathrm{O}\right)\end{array}$ & $10 \sim 20 \%$ & $10 \sim 25 \%$ \\
\hline Sulfidity & - & $0-30 \%$ \\
\hline $\begin{array}{c}\text { Addition of } \mathrm{AQ} \\
\text { derivatives }\end{array}$ & $0 \sim 0.1 \%$ & 0 or $0.05 \%$ \\
\hline L/B ratio ${ }^{*}(\mathrm{ml} / \mathrm{g})$ & 5 or 15 & 5 or 15 \\
\hline Temperature & $170^{\circ} \mathrm{C}$ & $170^{\circ} \mathrm{C}$ \\
\hline Rising time & $1 \mathrm{hr}$ & $1 \mathrm{hr}$ \\
\hline Holding time & $2 \mathrm{hr}$ & $2 \mathrm{hr}$ \\
\hline
\end{tabular}

* Liquor to bast ratio

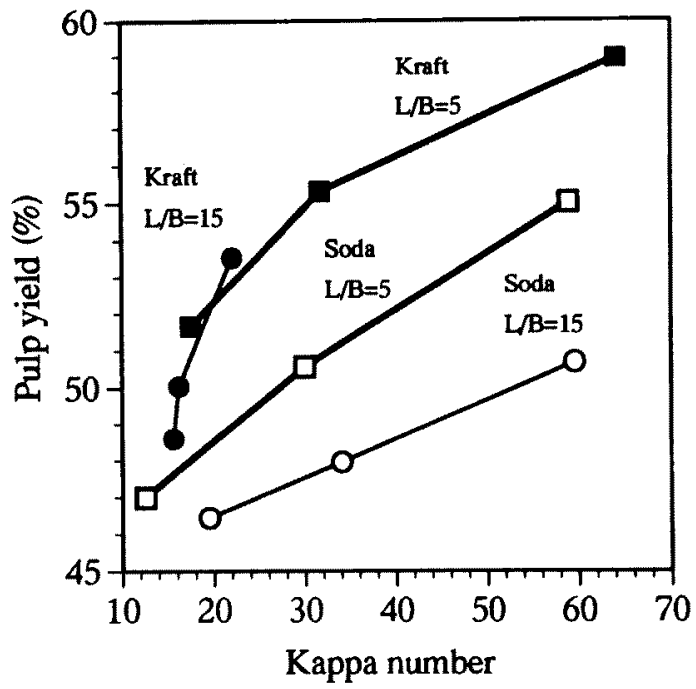

Fig. 1 Relationships between kappa number and pulp yield of soda or kraft pulps which were produced in different liquor-to-bast $(\mathrm{L} / \mathrm{B})$ ratios

rite and acetic acid were based on the kappa number of pulp (for example, $0.06 \mathrm{~g}$ of sodium chlorite and $0.05 \mathrm{~g}$ of acetic acid were used for the pulp having 20 of kappa number)

Each unbleached pulp fiber was stained with safranine and observed by microscope.

\section{Result and Discussion}

\subsection{Influence of $\mathrm{L} / \mathrm{B}$ Ratio on Cooking Results}

Initially, the suitable liquor to bast ratio (L/B ratio $(\mathrm{ml} / \mathrm{g})$ ) was determined because the kenal bast seemed to necessitate higher $L / B$ ratio than the wood due to its low density and high balkiness. Soda or kraft cooking results with two L/B ratios, 5 and 15 are shown in Fig. 1. Kraft cookings with 15 of $\mathrm{L} / \mathrm{B}$ ratio were carried out with about $5 \%$ higher alkali dosage. Kraft cooking gave higher pulp yield at the same kappa number level than soda cooking. Soda cooking indicated that the $L / B$ ratio 5 gave the better delignification at the same pulp yield, but kraft cooking showed little difference between $\mathrm{L} / \mathrm{B}$ ratio 5 and 15. Totally, lower $\mathrm{L} / \mathrm{B}$ ratio seemed to be favorable, therefore the $\mathrm{L} / \mathrm{B}$ ratio 5 was used for the following cooking experiments.

\subsection{Comparison of Chemical Pulping Methods}

The chemical pulping of kenaf bast and core has well examined, in which much of the laboratory testing has been based on soda-AQ pulping [8]. But, the pulping results were observed to vary widely according to the sam. ple difference, therefore the pulping experiments with our identified samples were necessary.

The pulp yield, kappa number, and pulp viscosity, are shown in Fig. 2-Fig. 4, respectively, as a function of the added active alkali. These figures also demonstrate the difference among the soda, soda-THAQ and kraft cooking results. In these experiments, THAQ was used instead of $A Q$. The kraft cooking gives a bit higher pulp yield $(1-2 \%)$ than the other two, but the kappa numbers of the kraft and soda-THAQ pulps which show little difference each other, are much lower than that of soda pulp (Fig. 2,3 ). It means that soda.THAQ cooking is almost equal to the kraft cooking with respect to the delignification ability. The viscosity of kraft pulp is a little higher in the range of lower active alkali dosage of 10-12\%, but decreases to the same level of soda and soda-THAQ pulps at higher active alkali dosage of about $15 \%$ (Fig. 4). The kraft pulping for kenaf bast seems to be the best regarding the pulp yield, kappa number, and pulp viscos. ity, but there is only a little difference in pulping results between the soda-THAQ and kraft cookings.

\subsection{Effects of AQ Derivatives on the Soda Pulping of Kenaf Bast}

The relations between pulp yield and kappa number in soda-AQ derivatives cookings are shown in Fig. 5. Addition of soda and $\mathrm{AQ}$ derivatives are $10-15 \%$ as $\mathrm{Na}_{2} \mathrm{O}$ and $0.05 \%$, respectively. All $\mathrm{AQ}$ derivatives, viz. $\mathrm{AQ}$. $T H A Q$, and $S A Q$ are effective for the delignification to nearly the same extent, and the cookings with them are far superior to the soda cooking. SAQ is usually known as a most effective agent for the wood pulping [9], but 


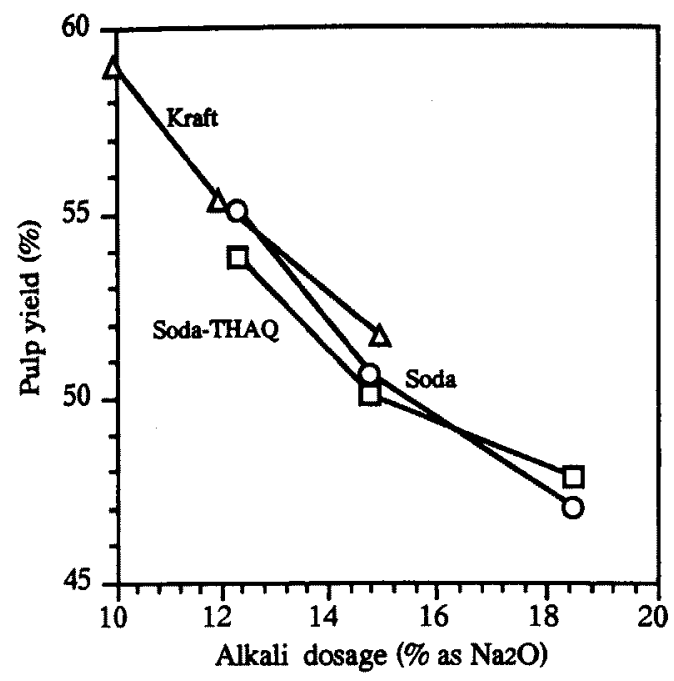

Fig. 2 Relationships between alkali dosage and pulp yield in the alkaline pulpings.

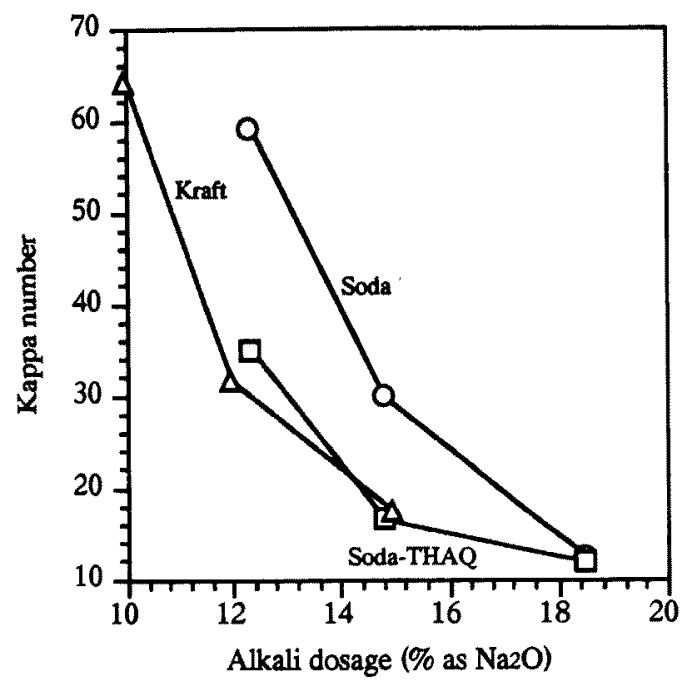

Fig. 3 Relationships between alkali dosage and kappa number in the alkaline pulpings.

these results indicate that it is rather worst among above three additives in the kenaf bast pulping. This might be caused from the difference in the chemical compositions between kenaf bast and wood. Usually, kenaf bast con. tains $10-25 \%$ of water-soluble components which depend on maturity, harvesting and storage time of kenaf plant [10]. In the case of kenaf core which contained lower water-soluble contents, SAQ was the best among three additives [11]. Therefore, large quantities of these com. ponents are considered to slightly affect the stabilization

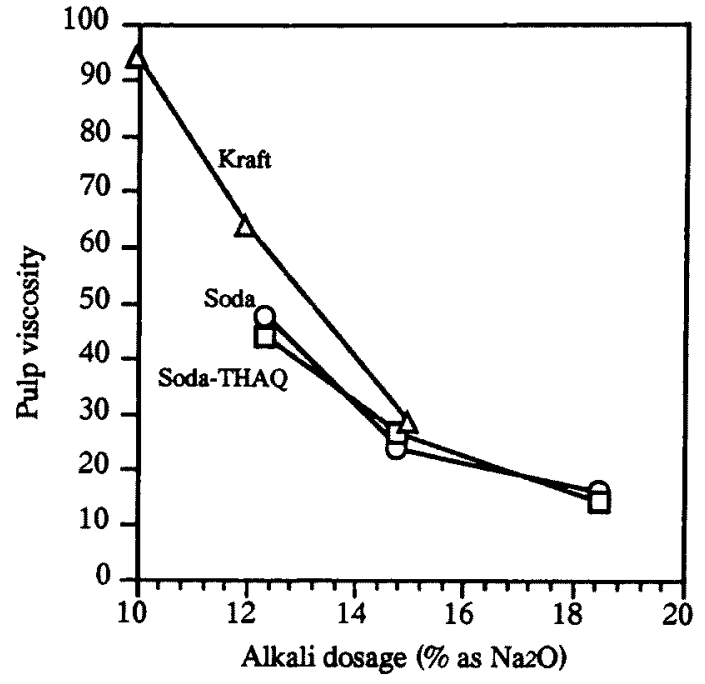

Fig. 4 Relationships between alkali dosage and pulp viscosity in the alkaline pulpings.

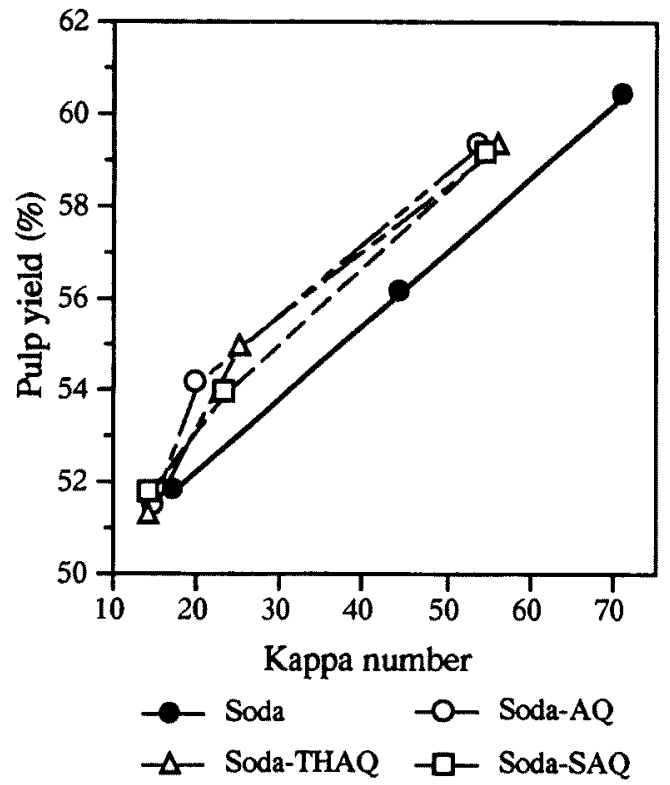

Fig. 5 Relationships between kappa number and yield of pulps from soda.AQ derivative pulpings.

of $S A Q$ or the penetration of other $A Q$ derivatives.

\subsection{Kraft Pulping with AQ}

AQ has been added into kraft pulping of wood for the purpose of increasing pulp yield and accelerating deligni. fication (12), therefore these two distinctive roles were investigated for the kenaf bast pulping. Six pulping experiments were conducted to determine the effect of sulfidity on kraft-AQ pulping of kenaf bast. The active alka- 


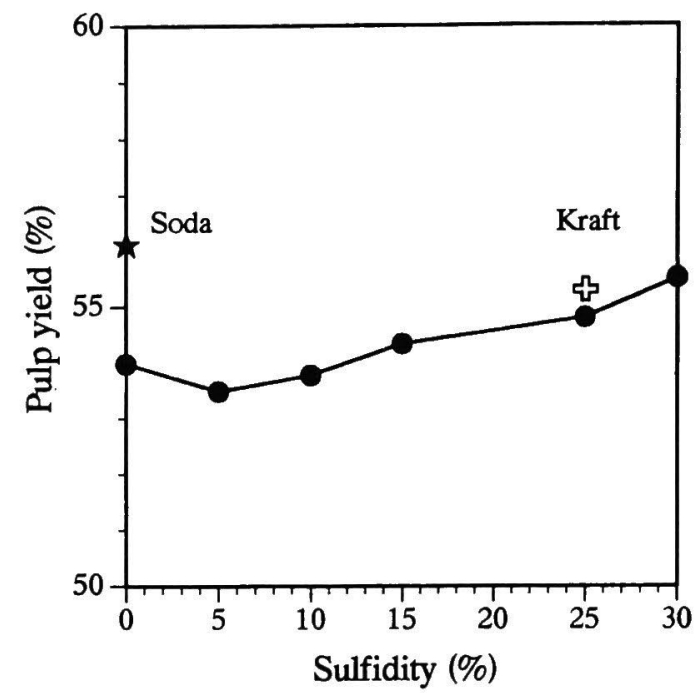

Fig. 6 Pulp yields as a function of pulping liquor sulfidity in kraft.AQ pulping.

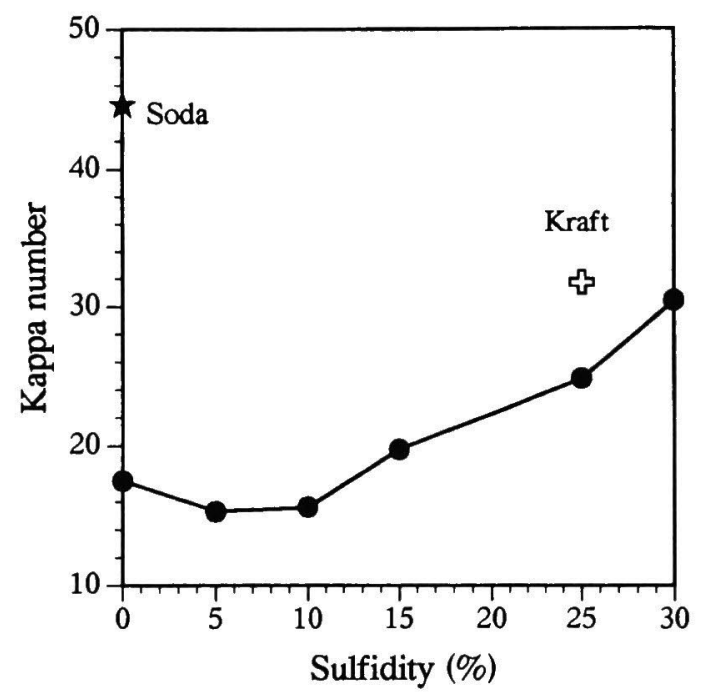

Fig. 7 Kappa numbers as a function of pulping liquor sufidity in kraft.AQ pulping.

li and the $\mathrm{AQ}$ additions were held constant at $12 \%$ and $0.05 \%$ by weight, respectively. The sulfidity was varied from $0 \%$ to $30 \%$ over the various cooks. The results are shown in Fig. 6 and Fig. 7 which also include the data of soda and standard kraft pulping (sulfidity 25\%). Addition of $A Q$ remarkably lowers the kappa number, and also decreases the pulp yield slightly. These effects are large when the sulfidity is low. Comparison of standard kraft and kraft-AQ cooking at $25 \%$ of sulfidity indicates that $\mathrm{AQ}$ decreases the pulp yield as well as the kappa

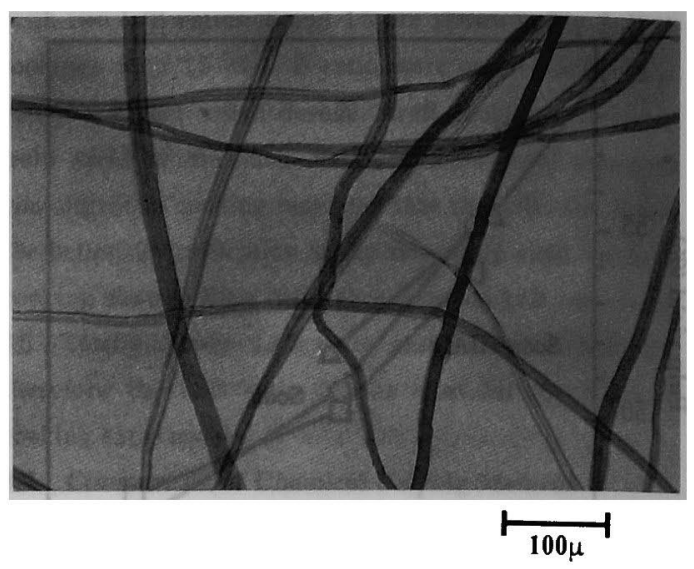

Fig. 8 Microphotograph of kenaf bast fibers from soda$\mathrm{AQ}$ pulping.

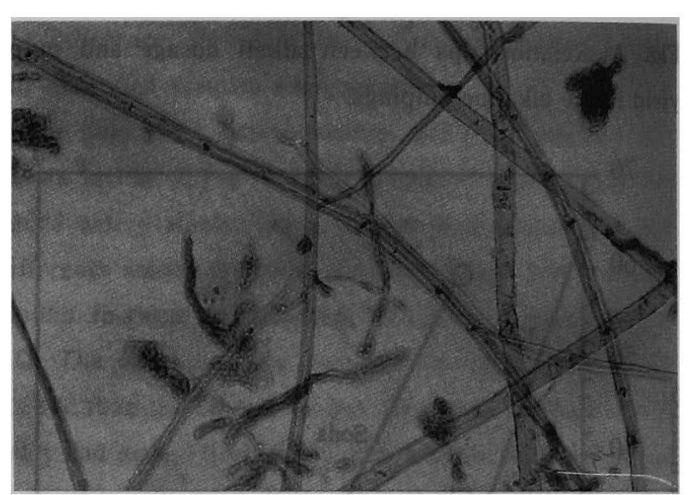

Fig. 9 Microphotograph of mitsumata fibers.

number. It means that $\mathrm{AQ}$ does promote delignification but doesn't act so effectively toward carbohydrate stabilization.

\subsection{Microscopic Observation of Kenaf Bast Pulps}

Microscopic appearance of kenaf bast fibers from different pulping methods resembled each other. Mic. rophotographs of the kenaf bast fibers from soda-AQ pulping and the commercial mitsumata fibers are shown in Fig. 8 and Fig. 9, respectively. Kenaf bast fibers are thought to be alternative to some woody bast fibers, especially mitsumata fibers because their dimensions are similar to those of mitsumata fibers which are $10 \sim 20$ $\mu \mathrm{m}$ wide and about $2.3 \mathrm{~mm}$ long. However, characteristics of these fibers have not been compared in detail. Kenaf bast fiber is found to have large microfibril angle [4] and be susceptible to internal fibrilation by beating [13]. Kozo fiber also have large microfibril angle, but mitsumata fiber has small one [4]. These findings suggest 
some differences between kenaf bast fiber and other woody bast fibers exist, therefore further investigations should be done to confirm the viability for utilization of kenaf bast fiber as an alternative to woody bast fibers.

\section{Conclusion}

Soda.AQ pulping will be preferred for the kenaf bast, because the resulting pulp has slightly lower pulp yield but are at the same lignin content and pulp viscosity levels when compared to the kraft pulp, and the environ. mentally acceptable non-sulfur cooking and lower invest. ment cost could be achieved.

\section{References}

1. A. F. Kaldor, Proc. 2nd Int. Non wood Fiber Pulping and Papermaking Conf., p. 232, 6-9, April, 1992.

2. K. Hara, Kami Parupu Gijutu Taimusu, p. 5, March.
1994.

3. K. Sameshima, Proc. 1992 Tappi Pulping Conf. Book 2. p. 603 .

4. H. Nanko et. al., Proc. of $1983 \mathrm{Int}$. Symp. on Wood and Pulping Chem., Vol. 4, p. 1.

5. Technical Report, Kawasaki Kasei Kogyo Co.

6. Tappi standard method T $236 \mathrm{hm} \cdot 85$.

7. Japan Tappi testing method No. 44-84.

8. A. F. Kaldor, C. Karlgren, and H. Verwest, Tappi J., $73[11], 205$ (1990).

9. Y. Nomura, Japan Tappi, 32, 713 (1978).

10. T. F. Clark and I. A. Wolff, Tappi, 52, 2111 (1969).

11. T. Noguchi et al., unpublished data.

12. L. Lowendahl and O. Samuelson, Tappi, 62 [2] , 19 (1978).

13. K. Hara et. al, Japan Tappi, 32. 599 (1978). 